\title{
Turn of the Century Activities: From Grenoble to Montreal
}

\author{
Werner Schiehlen
}

A first report on the activities of IUTAM, the International Union of Theoretical and Applied Mechanics, covering the first forty years of the Union from 1946 to 1986 was composed by J. Hult and N.J. Hoff, and incorporated in the first edition of this book edited by S. Juhasz. This update of IUTAM's history edited by P. Eberhard is devoted to the next thirty years from 1988 to 2016 including the turn of the century. In the following, the developments are described which came up during that period.

\section{A. Adhering Organizations}

Organizations of scientists in theoretical or applied mechanics that effectively represent independent scientific activity in a country or in a definite territory can be admitted by the General Assembly as Adhering Organization of the Union. Each adhering organization has representatives in the General Assembly of the Union with voting rights, and pays annual dues to the Union.

The number of Adhering Organizations admitted by IUTAM during the last thirty years increased from 37 to 48 in the year 2015. The number has been changing due to new admittances or suspensions, respectively, as follows.

\footnotetext{
W. Schiehlen $(* 1938)$

University of Stuttgart, Stuttgart, Germany

(C) The Author(s) 2016 


\section{Admittances}

- 1988 Saudi Arabia

- 1990 Vietnam, Korea

- 1994 South Africa

- 1996 Chile, China-Hong Kong

- 2008 Mexico

- 2010 Cyprus

\section{Changes of Territories and Suspension}

- 1990 Unification of Germany, then FRG and GDR are jointly represented again

- 1992 Dissolution of USSR, then separately represented by Russia (1992), Estonia (1992), Georgia (2000), Ukraine (1995)

- 1993 Dissolution of Czechaslowakia, then partially represented by Czech Republic (1993)

- 1994 Dissolution of Yugoslavia, then separately represented by Croatia (1994), Serbia (2003), Slovenia (1994)

- 2013 Suspension of Argentina

For more details see the appendices. The current list of Adhering Organizations is also available at IUTAM's website.

\section{B. Affiliated Organizations}

International organizations mainly occupied in fields closely related to that of IUTAM can be admitted by the General Assembly as Affiliated Organization of the Union. Each Affiliated Organization has the right to appoint an observer, who is invited to take part in the General Assembly without voting rights. The IUTAM Bureau has the reciprocal right to appoint a nonvoting observer to the corresponding council or other executive body of the Affiliated Organization.

The number of Affiliated Organizations admitted by IUTAM during the last thirty years increased from 10 in 1984 to 20 in 2015. The following organizations have been newly affiliated in this period.

- Latin American and Caribbean Conference on Theoretical and Applied Mechanics (LACCOTAM), 1992/2010

- International Association for Boundary Element Methods (IABEM), 1994

- International Society for Structural and Multidisciplinary Optimization (ISSMO), 1996 
- International Association for Hydromagnetic Phenomena and Applications (HYDROMAG), 1996

- International Institute of Acoustics and Vibration (IIAV), 1997

- International Commission for Acoustics (ICA), 1998

- International Congresses on Thermal Stresses (ICTS), 2002

- Beijing International Center for Theoretical and Applied Mechanics (BICTAM), 2010

- International Association for Multibody System Dynamics (IMSD), 2014

- International Association for Structural Control and Monitoring (IASCM), 2014

This list shows clearly the wide extension of fields of mechanics closely related to theoretical and applied mechanics. Thus, IUTAM represents not only most nations considering mechanics as a science but also many related fields beyond fluid mechanics, solid mechanics and dynamics. A current list of Affiliated Organizations is available at IUTAM's website, too.

\section{Changing Activities}

The main activities of IUTAM include the organization of International Congresses of Theoretical and Applied Mechanics (ICTAM) through a standing Congress Committee, and the support of IUTAM Symposia and Summer Schools for subjects falling within the field of theoretical and applied mechanics. Moreover, to strengthen the scientific cooperation between IUTAM and its Affiliated Organizations, Working Parties were established for a limited period from 1996 to 2014.

\section{World Congresses}

The scientific program of the congresses followed, until the ICTAM 1980 in Toronto, more or less the same pattern, namely Opening and Closing Lecture at plenary sessions, and invited Sectional Lectures and Contributed Papers in parallel lecture sessions. Major changes were implemented at ICTAM 1984 in Lyngby. To highlight recent topics of special emphasis three Minisymposia within ICTAM were selected. Due to the great success, since ICTAM 1996 in Kyoto six Minisymposia are included in the Congress.

Minor changes resulted in strengthening the invited sectional lectures which are now scheduled exclusively in parallel beginning with ICTAM 2000 in Chicago. The number of these keynote lectures amounted between 12 and 20 during the last thirty years. More details on the World Congresses are listed in the appendices. 


\section{Scientific Symposia}

The aim of an IUTAM symposium is to assemble a group of active scientists within a well-defined field for the development of science within that field. In order to achieve an effective communication within this group it is necessary to limit the number of active participants. To this end, all IUTAM Symposia are reserved for invited participants. Those wishing to participate in an IUTAM Symposium are therefore advised to contact the Chairman of the Scientific Committee in due time in advance of the meeting.

Following proposals made by individual members of the IUTAM General Assembly and recommendations given by the two IUTAM Symposia Panels and by the IUTAM Bureau, the General Assembly decides upon topics to be treated at forthcoming symposia. The IUTAM Bureau then appoints a Scientific Committee, which will become responsible for the symposium. The Scientific Committee proposes the date for the symposium, subject to approval by the Bureau.

The Secretary-General of IUTAM informs the Chairman of the Scientific Committee about the Rules and the Guidelines, issued by the IUTAM General Assembly and keeps him continually informed about any decisions regarding his Symposium, which may be taken by the General Assembly or the Bureau. The main responsibility of the Scientific Committee is the selection of scientists to be invited. It is responsible for the publication of the proceedings of the Symposium and for the distribution of the grants by IUTAM to participants.

Due to the great success, scope and format of IUTAM Symposia have not been changed. But their topics widened. In the first forty years the symposia dealt mainly with Fluid and Solid Mechanics, Dynamics and Control as well as Foundations of Mechanics. More recently topics like Bio and Earth Sciences, Fluid Structure Interaction, Materials, Micro- and Nano-Mechanics, Computational Mechanics, and Optimization evolved. Nevertheless, the number of IUTAM Symposia remained due to the strong review process between 7 and 10 per year.

Detailed information on the Symposia is collected in the appendices.

\section{Summer Schools}

The IUTAM Summer Schools were established 1990 in cooperation with the International of Centre for Mechanical Sciences (CISM), our first Affiliated Organization. By tradition, IUTAM sponsors one summer school per year, usually in cooperation with CISM. Exemptions have been Summer Schools in Aalborg, Denmark (1994), Stockholm, Sweden (1995), Beijing, China (2001, 2002 and 2004), Evanston, USA (2010) and West Lafayette, USA (2012). 


\section{Working Parties}

At the 1996 General Assembly six IUTAM Working Parties (WPs) were temporarily appointed to initiate a closer cooperation with the organizations affiliated with IUTAM as follows.

- WP 1: Mechanics of Non-Newtonian Fluids (ICR)

- WP 2: Dynamical Systems (IAVSD)

- WP 3: Fracture Mechanics and Damage (ICF)

- WP 4: Mechanics of Material (ICM)

- WP 5: Electromagnetic Processing (HYDROMAG)

- WP 6: Computational Mechanics (IACM)

Then, later the Working Parties were reviewed, one of them dissolved and four new ones added representing timely scientific fields. The 2002 General Assembly approved the following nine Working Parties.

- WP 1: Mechanics of Non-Newtonian Fluids

- WP 2: Dynamical Systems

- WP 3: Mechanics of Material

- WP 4: Material Processing

- WP 5: Computational Mechanics

- WP 6: Biomechanics

- WP 7: Nano- and Macro-Scale Phenomena in Mechanics

- WP 8: Geophysical and Environmental Mechanics

- WP 9: Education in Mechanics and Capacity Building

In 2014, the General Assembly terminated the activities of the Working Parties.

To strengthen the subfields of mechanics, certain working parties may be revived again by commissions which are established with many ICSU unions, too. These kinds of activities may become interesting again for IUTAM in the future.

\section{Statutes, Rules, and Procedures}

The original version of the IUTAM Statutes was adopted in 1947 and ICSU, the International Council for Science, accepted IUTAM in the same year as adhering body. The International Council for Science (ICSU) is a non-governmental organisation with a global membership of national scientific bodies (as of 2015 there are 121 members, representing 141 countries) and International Scientific Unions (32 members).

Now, the changes of the Statutes and the Rules of Procedure during the last three decades will be reviewed. 


\section{Statutes}

- 1990 In Article VI the Bureau members were added as ex officio members of the General Assembly of the Union. Their terms of membership shall coincide with their term of service on the Bureau.

In Article XI it was stated that the other members of the Bureau not serving as officers shall have been members of the General Assembly at some time within the four years preceding the time of election of the Bureau.

- 1994 A new Article XV was added stating that an alteration of the Statutes requires proposals either prepared by the Bureau or supported by statements to the General Assembly signed by at least ten of its voting members.

- 2004 In Article II the principle objectives of the Union were extended to scientific work in all branches of theoretical and applied mechanics and related sciences, including analytical, computational and experimental investigations.

Article VI was extended to distinguish between voting members and observers without voting rights. The voting members are representatives of the adhering organizations, members of the Bureau, and members-at-large. The term of a member-at-large shall be determined by the General Assembly at the time of the election. The following categories of observers are invited to take part in the General Assembly: representatives of affiliated organizations; Secretary of the Congress Committee; chairs of the Symposia Panels; chair persons of the Working Parties; representatives of countries applying for membership; representatives of committees and groups of scientists, if so decided by the General Assembly.

- 2008 In Article VI the representatives of Adhering Associate Organizations have been added to the observer categories.

A new Article IX was added introducing the adhering associate organisations for countries or territories of the developing world. As a consequence the Articles IX to XIV from 2004 were renumbered as Articles X to XV.

Article XIV was extended by adding the subscriptions of the adhering associate organizations.

A new Article XVI was added to specify the subscription payments of the adhering associate organisations.

As a consequence Article XV from 2004 was renumbered as Article XVII.

- 2014 Article VI was changed. The Secretary of the Congress Committee and the Chairs of the Symposia Panels appointed by the Bureau were moved from the observer category to full members of the General Assembly with voting rights. Article XII was specified with respect to the candidates for all seven positions to be elected for the Bureau. These candidates must have been full voting members of the General Assembly.

In Article XIIIb it is stated that the Secretary of the Congress Committee shall be nominated by the Congress Committee and elected by the General Assembly for a four year term with the possibility of re-election for a second term. 
Article XIIIc defines now the election of the members of the Congress Committee from nominations invited by the Secretary of the Congress Committee.

Article XIIId specifies now the election of the Executive Committee of the Congress Committee by the General Assembly.

\section{Procedures}

- 1992 The procedure for electing Members-at-Large of the General Assembly was established.

- 1994 The procedure for election of the Bureau of IUTAM was specified in detail. The Electoral Committee (EC) shall invite suggestions, take account of, and submit to the Secretary General nominations for the candidates for the election to the Bureau: one name for each of the Officer positions $(\mathrm{P}, \mathrm{S}, \mathrm{T})$ and one or more names for each of the non-Officer positions (W, Y, X, Z). The EC will make sure that the candidates thus nominated are willing to accept an election. The General Assembly shall vote separately on each of the seven positions. In any case in which there is more than one candidate for a position, the vote shall be by secret ballot.

- 2004 The procedure for election of the Bureau of IUTAM was further specified. The invitation of suggestions was restricted to the voting members of the General Assembly, the representatives of affiliated organisations and the Secretary of the Congress Committee.

- 2008 Rules of procedure for Adhering Associate Organisations were established with respect to the prime criteria for the eligibility of any country, and the rights and privileges of Associate Members included.

- 2014 Rules of procedure for the Congress Committee of IUTAM were specified as follows: During an International Congress, the $\mathrm{CC}$ shall review proposals for the next International Congress and select the location by a vote of the $\mathrm{CC}$ members present (i.e., proxy votes are not permitted). This selection process will typically be accomplished over two separate meetings of the CC.

All these changes of the Statutes and the Procedures are evidence of the IUTAM's leading role in the sciences based on mechanics with many analytical, computational and experimental fields within ICSU, the International Council of Science. The organizational structure of IUTAM has proven to be capable and efficient. Close scientific cooperation and personal long-lasting friendship are reasons for IUTAM's success. The organizational structure of IUTAM is shown in the following figure. 


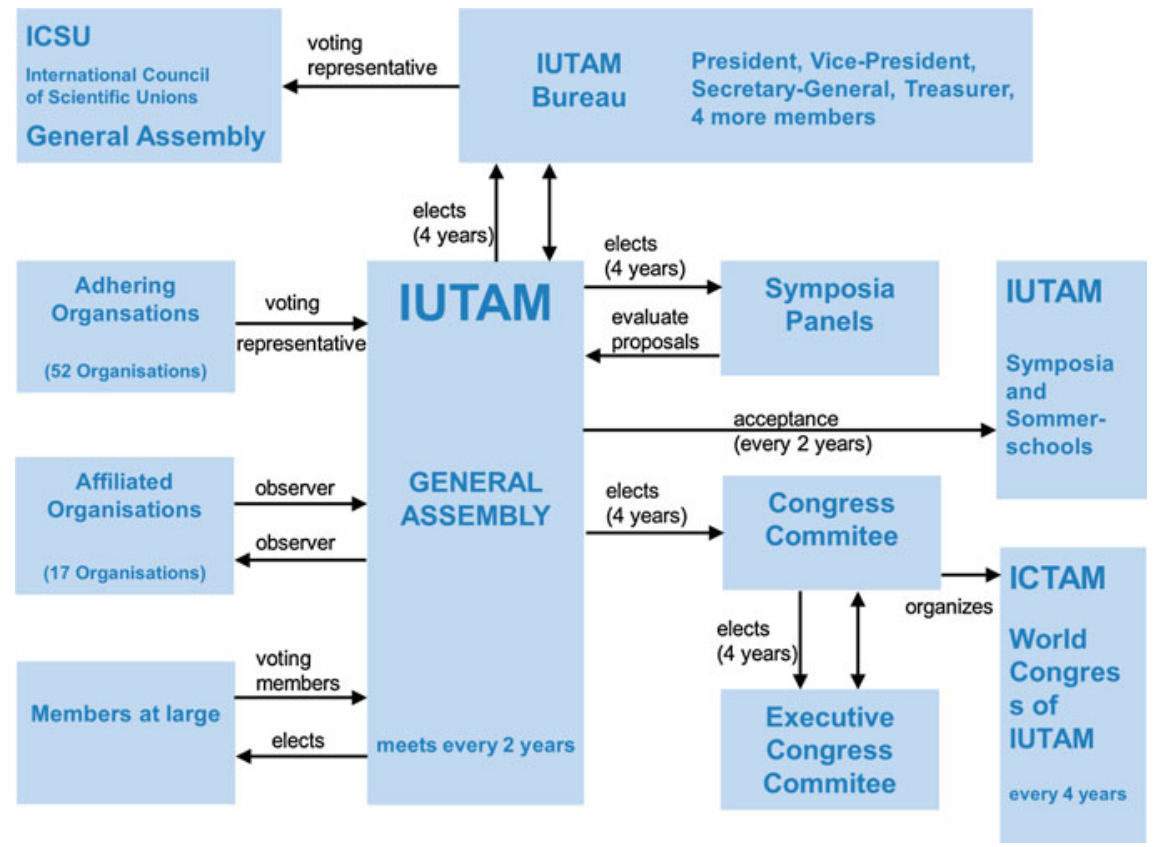

\section{E. Publications}

The first publication considered as an IUTAM publication dates back to the Proceedings of the First International Congress of Applied Mechanics held 1924 in Delft, The Netherlands. It was simply entitled as "Applied Mechanics". Later on in 1972, since the 13th Congress, the Proceedings were entitled as "Theoretical and Applied Mechanics" and the Congress abbreviation ICTAM was used. The congress proceedings were published in cooperation with commercial or academic publishers. In this century, the titles of the Proceedings were more individually chosen as "Mechanics for a new Millenium", "Mechanics for the 21st Century", "Mechanics Down Under" and "Mechanics for the World".

Since the foundation of IUTAM all its activities are documented in Annual Reports in great detail published by the IUTAM Secretariat. The first volume of IUTAM Symposia Proceedings was published in 1949. Symposia proceedings may appear as books or special issues of journals in cooperation with commercial companies. From January 1996 until December 2010, Springer Science and Business Media (named Kluwer Academic Publishers until 2004) has been the preferred publisher of the refereed proceedings of IUTAM symposia under the title IUTAM Bookseries. Since January 2011, Procedia IUTAM by Elsevier is the preferred medium of publication for the refereed proceedings of IUTAM symposia and ICTAMs. It is open access. 
An IUTAM Newsletter was established in 1992 and it is distributed widely by the IUTAM Secretariat. The Newsletter contains usually a President's Address, a short report on General Assembly and Congress Committee meetings as well as announcements on the forthcoming ICTAM, IUTAM Symposia and Summer Schools, and IUTAM co-sponsored events.

The first publication on the short history of IUTAM dates back to 1988, it was edited by S. Juhasz and published by Springer-Verlag. On the occasion of the millennium the booklet "Mechanics at the Turn of the Century" was edited by W. Schiehlen and L. van Wijngaarden and published by Shaker Verlag. This report was the result of an initiative of the Bureau of IUTAM to provide some landmarks on the developments in mechanics during the 20th Century, to report on the 50 years of impulse to mechanics by IUTAM, to visualize the history of mechanics by the water colour Meters of Motion painted on the occasion of the 20th ICTAM, to look ahead on a very personal basis, and to show the broad international involvement of scientists in IUTAM in recent years.

The bibliographical details of the broad spectrum of IUTAM related publications are available in the appendices and on the IUTAM website.

\section{F. Celebrations}

Looking back to the history of IUTAM there are anniversaries to be celebrated from time to time. Three of them are mentioned here.

\section{6: 50th Anniversary of IUTAM}

In 1996 during the 19th ICTAM hold in Kyoto, Japan and presided by T. Tatsumi the 50th anniversary of IUTAM was celebrated. For this purpose all Congress participants received in their registration case a small booklet entitled "IUTAM, 1946-1996: Fifty Years of Impulse to Mechanics" published by Kluwer Academics. The author Fonts Alkemade is a science writer from Amsterdam, The Netherlands. He got in contact to mechanics writing 1994 a biography on Jan Burgers included in the book "Selected Papers of J.M. Burgers" edited by F.T.M. Niewstadt and J.A. Steketee, and published by Kluwer Academic Publishers.

\section{0: Mechanics for a New Millennium}

A unique event to celebrate the past and future of IUTAM was the 20th ICTAM hold in Chicago, USA. The subtitle of this Congress phrased by its President Hassan Aref was "Mechanics for a New Millennium". 
The watercolour "Meters of Motion" by Champaign-Urbana artist Billy Morrow Jackson was the basis for the poster announcing the 20th International Congress of Theoretical and Applied Mechanics, held in Chicago in August 2000. The ICTAMs, initiated in 1924, have visited many of the great cities of the world: Copenhagen, Delft, Grenoble, Haifa, Istanbul, Kyoto, London, Moscow, Munich, Paris, Stockholm, Toronto, and Zürich among them. They are the "Olympic Games" of the science of mechanics, international forums where scientists and engineers from around the world meet every four years to present and discuss the latest results in the oldest of the physical sciences, the science of mechanics.

This beautiful watercolour tells the whole history of mechanics as a science starting with Archimedes, Galilei and Newton up to now as indicated by the team holding and standing on the IUTAM bridge.

Over the bridge to the right we find past officers of IUTAM: past presidents Sir James Lighthill, Paul Germain, Leen van Wijngaarden, Werner Schiehlen and Daniel C. Drucker. We also see past secretaries of IUTAM's Congress Committee, Niels Olhoff and H. Keith Moffatt. The president of the 19th Congress in Kyoto, Tomomasa Tatsumi, is in the middle of this group. Holding up the bridge are the President and Secretary-general of the 20th Congress, Hassan Aref and James Phillips of the University of Illinois at Urbana-Champaign.

More details are found in the book "Mechanics at the Turn of the Century" which was edited by W. Schiehlen and L. van Wijngaarden and published by Shaker Verlag.

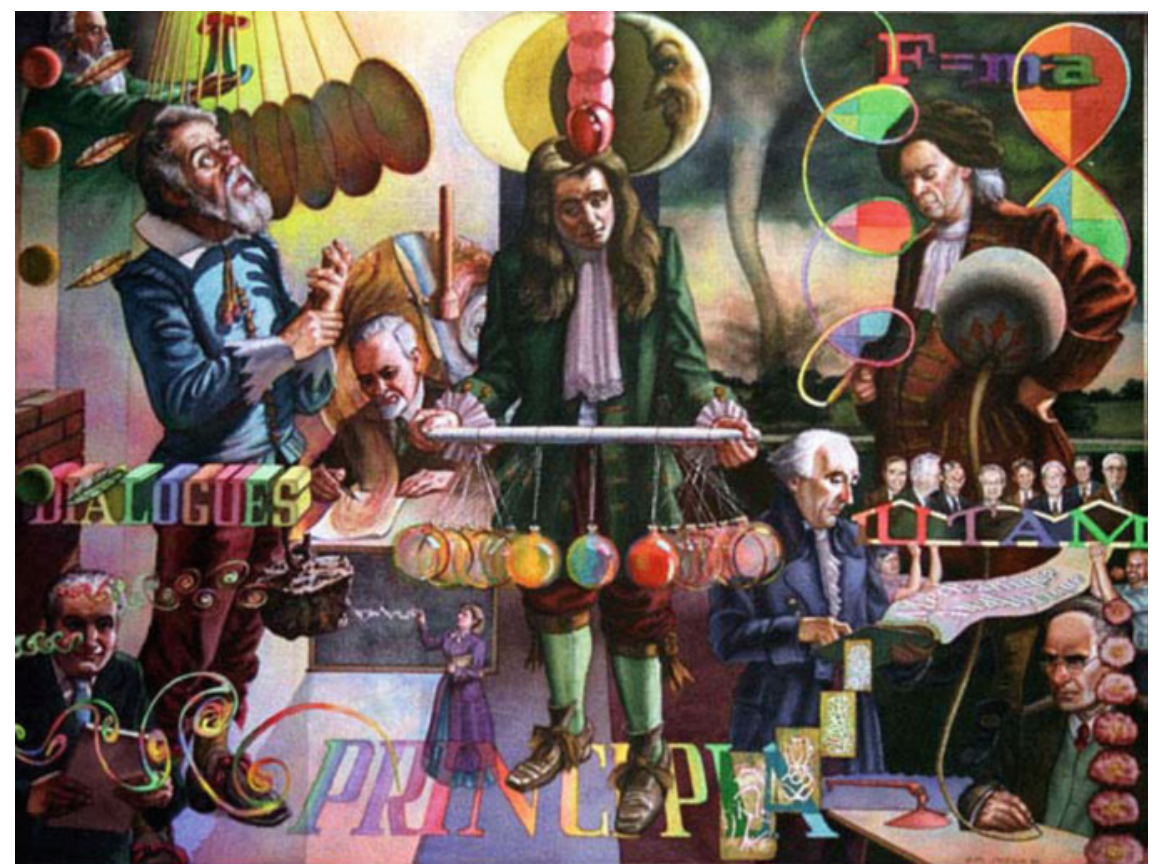




\section{4: 80th Anniversary of ICTAM}

The first International Congress of Applied Mechanics took place 1924 in Delft and this year is considered as the year of foundation of the ICTAMs long before the establishment of IUTAM. Chairmen of the first Congress were C.B. Biezeno and J. M. Burgers.

During the 21th ICTAM held in Warsaw, Poland the 80th anniversary was highlighted by the President of IUTAM, K. Moffatt from Cambridge, UK, featuring the close connection between ICTAM and IUTAM again. The subtitle of the congress was "Mechanics for the 21th Century" chosen by its President W. Gutkowski.

\section{6: 70th Anniversary of IUTAM}

As already mentioned, IUTAM was created 1946 during the 6th Congress for Applied Mechanics held in Paris, France. The Statutes of IUTAM are still available today in French, and the 24th ICTAM takes place 2016 in Canada's French speaking province Quebec with the metropolis Montreal. The French title of ICTAM 2016 is also easily understood "La mécanique-fondement de la recherché multidisciplinaire". During ICTAM 2016 this second edition of the book "IUTAM -A Short History" published again by Springer will appear online with free access for everybody including all the participants of the Congress to celebrate the 70th anniversary.

\section{G. Prizes}

The prizes awarded by IUTAM are closely related to the ICTAMs. There are two categories, the IUTAM Bureau prizes for young scientists and the Batchelor and Hill Prizes for scientists doing research on an emerging field or with a significant breakthrough within one full decade.

\section{IUTAM Bureau Prizes}

Beginning with the 17th International Congress in Grenoble (1988), the Bureau of the International Union of Theoretical and Applied Mechanics has selected 2 or 3 outstanding young scientists for the Bureau Prize, based on their papers and their presentations at the Congress. To be eligible for the award, a presenter must be not older than 35 years of age at the time of the Congress, and must indicate that he/she wishes to be considered for the award. The award includes a certificate and a check 
of 500 USD. The recipients are announced during the closing session and on IUTAM's web page.

\section{Batchelor Prize}

The Batchelor Prize, sponsored by the Journal of Fluid Mechanics, is presented once every four years at the ICTAM since the 22nd ICTAM in 2008. The prize winner is announced late in the year prior to the Congress.

The prize of $\$ 25,000$ is awarded to a single scientist, for outstanding research in fluid dynamics. The research so recognised by the prize shall normally have been published during the ten year period prior to the announcement of the award.

The prize winner is determined by a small committee whose members are internationally distinguished experts in fluid mechanics. It is expected that the prize winner delivers a lecture at ICTAM and that this lecture will also be published in the Journal of Fluid Mechanics and be made freely available on the Cambridge University Press Journals website.

\section{Hill Prize}

Elsevier has established a prize named The Rodney Hill Prize in Solid Mechanics. This prize, which consists of a plaque and a check for $\$ 25,000$ is to be awarded in recognition of outstanding research in the field of solid mechanics. The prize is awarded every 4 years, to coincide with the quadrennial International Congress of Theoretical and Applied Mechanics (ICTAM).

An article based on the lecture shall be published in the Elsevier journal of the awardee's choice (as well as in the Congress Proceedings at the awardee's discretion), and shall be made freely available on the journal website.

The Prize winner is selected by a Selection Committee consisting of four members appointed by the IUTAM Bureau and constituted as follows: two chosen by Elsevier; one chosen by the Bureau of IUTAM; and one chosen by the Executive Committee of the Congress Committee (XCCC) of IUTAM.

\section{H. Concluding Remarks}

During the past thirty years the principal objectives of IUTAM have proven again to be most valuable guidelines for its scientific leadership. The Union's objectives are based on the tradition of free international scientific cooperation, developed in the International Congresses for Theoretical and Applied Mechanics (ICTAM), and they shall observe the basic policy of non-discrimination and affirm the rights of 
scientists throughout the world to adhere to or to associate with international scientific activity regardless of race, religion, political philosophy, ethnic origin, citizenship, language or sex.

One of the reasons for the continuous success of IUTAM is the strong interplay between analytical methods and demanding applications in science and technology. Even if mechanics is sometimes described as a completed science within physical sciences it turns out that the multi-disciplinary approach of theory and applications is very attractive for young scientists fascinated by combining hard sciences with demanding applications.

The number of adhering organizations from countries and territories, respectively, was further increasing as well as the fields closely related to fluid mechanics, solid mechanics and dynamics. The rules of procedure represented by the Statutes have been steadily adapted to recent developments and new experiences for smoother cooperation. As a result personal contact and long lasting friendship often happens between scientists working within the fields represented by IUTAM. Therefore, ICTAM Congresses, IUTAM Symposia and Summer Schools are frequently experienced as reunions of scientists supporting their international relations and serving as worldwide scientific marketplaces.

From its foundation in Paris 1946 to the 24th ICTAM in Montreal 2016 IUTAM has shown a steady growth and is highly respected worldwide. It is expected that the spirit of cooperation will continue in the future and IUTAM will operate solely for the advancement of mechanics and the good of mankind.

Open Access This chapter is distributed under the terms of the Creative Commons AttributionNoncommercial 2.5 License (http://creativecommons.org/licenses/by-nc/2.5/) which permits any noncommercial use, distribution, and reproduction in any medium, provided the original author(s) and source are credited.

The images or other third party material in this chapter are included in the work's Creative Commons license, unless indicated otherwise in the credit line; if such material is not included in the work's Creative Commons license and the respective action is not permitted by statutory regulation, users will need to obtain permission from the license holder to duplicate, adapt or reproduce the material. 